charge. Measurements made over the oceans by American observers in the non-magnetic ship Carnegie showed that there is a maximum effect all over the world at the same universal time $(7 \mathrm{p} . \mathrm{m}$. G.M.T.). It is now believed that the maintenance of the earth's charge is due to thunderstorms, which send an appreciable amount of negative electricity into the ground. In the upper atmosphere, the electrification is a thousand times denser than it is in the lower atmosphere. The marked solar control of the density indicates unmistakeably that the ionisation is due to solar radiation, and radio observations show that the cause of the electrification is ultra-violet light. A difference in the behaviour of the lower and upper levels of the ionosphere has been recognised recently. The lower stratum is found to be about twice as dense in summer as in winter, due to the more direct influence of sunshine. This is exactly the amount of variation predicted by theory. But for the higher region there is not the expected increase in summer. To account for this anomaly the theory has been put forward that, at a height of 150-200 miles, the atmosphere is raised to a high temperature by the sun. Expansion results from this heating, so that the electricity is attenuated in density. To account for the observed facts it appears necessary to assume that at this level the summer noon temperature is at least $2000^{\circ} \mathrm{F}$. The density of the ionosphere appears to follow the sunspot cycle of 11 years. The minimum of solar activity occurred about the latter half of 1933, and both magnetic and radio observations now show that activity is increasing again. It is expected, as a result, that the radioengineer will find substantial differences in the wireless wave-lengths best suited for long-distance communication.

\section{Science Exhibition at Liverpool}

There was a record attendance at the fifth public exhibition and soirée arranged by the Associated Learned Societies of Liverpool and District at the Liverpool Technical College on October 26. The exhibition was opened by the Lord Mayor of Liverpool, and the Mayor of Bootle attended; they were received and shown round the exhibition-twentysix rooms arranged by twenty-three societies comprising more than two thousand members-by the president, Dr. H. J. W. Hetherington; chairman, W. Mansbridge ; deputy-chairman, W. S. Laverock, and the secretary, Miss E. Warhurst. Lectures included : "Race, Place and Nationality in Europe" by Prof. P. M. Roxby ; "Value of Milk in Nutrition" by Prof. H. J. Channon; "Spiders and their Silk" by S.T. Burfield; and "Recent Work on Vitamins and Hormones" by Dr. R. A. Morton. The Society of Chemical Industry showed films of crystal growth by H. Emmett, and citrous fumigation with cyanides. The bird room arranged by Eric Hardy included a working scale model of a proposed bird observatory or ringing-station for migration study in the area, the first photographs taken of the grey phalarope in Great Britain-by members of the Ornithological Section of the Liverpool Naturalists' Field Club- and a working model of a ship's oil separator as the solution to the waste oil menace to sea-birds: Dr. C. T. Green of the Liverpool Botanical Society exhibited an extensive series of hand-coloured photographic prints of British orchids, similar to his noted collection recently accepted by the British Museum. Diagrams and photographs from Bidston Observatory were shown by the Liverpool Astronomical Society, and short talks were given on meteorology and astronomy. Dr. W. B. Wright, district geologist of H.M. Geological Survey, showed his results of spore analysis of coals at the Liverpool Geological Society's room. There were also demonstrations and exhibits by the leading scientific firms and the Liverpool Corporation Electric Department.

\section{Recent Acquisitions at the Natural History Museum}

Among the recent acquisitions to the Department of Zoology is the Bird collection of reptiles and amphibians from eastern Asia Minor. This collection, consisting of 196 specimens, contains representatives of one new subspecies of lizard and of two others not previously represented in the Museum's collections. It is of especial interest as coming from a region which is comparatively little known and which is intermediate, both geographically and faunistically, between the better-known regions of Iraq and western Asia Minor. A collection of 280 land snails from Cyprus has been purchased and is of interest in connexion with an intensive study which is being made of insular variation in the land Mollusca of various Mediterranean islands. The Department of Geology has received the Pleistocene vertebrate remains (chiefly mammals) which have been collected by Dr. L. S. B. Leakey in considerable quantity and from a large number of localities in East Africa in the course of his recent expedition. Purchases for the Department include a number of rare fossil fishes from the Middle Eocene of Bolca, Italy. The Mineral Department has received by gift from $\mathrm{Mr}$. V. Koren a specimen of gold in quartz from Tangan. yika Territory; from Mr. E. E. A. Leach a large crystal of platinum, showing magnetic poles, from Potgietersrust, Transvaal ; from Dr. R. Kirkpatrick a series of moldavites, mostly collected by himself, from Czechoslovakia; and from Dr. Germaine Joplin a series of rocks from Ben Bullen, New South Wales. The purchases include a series of Brazilian minerals, among them being a large, pale blue and white, zoned, tabular, and waterworn crystal of topaz, a cut citrine (yellow quartz), weighing $647 \cdot 35$ carats, a large cut, pink and green tourmaline weighing 57.47 carats, a golden beryl crystal, and several specimens of quartz. A cut lemon-coloured orthoclase, weighing 31 carats, has also been bought.

THE Department of Botany has received from Mrs. E. G. Wheelwright the bryological herbarium of the Rev.H. E. F. Garnsey (1826-1903). The collection contains 2,300 mosses mostly British. Though Garnsey's name is best known on account of his association with the translations of German botanical textbooks issued by the Oxford Press, he had a high reputation 